\title{
Utilization of both Electronical Manganese Slag and Silicate Tailings as Raw Materials for Fabrication of Cost-effective Porous Ceramics
}

Hongfu Lin

Central South University

Mengke Li

Central South University

Zhiguo He ( $\nabla$ zghe@csu.edu.cn )

Central South University

Hui Zhong

Central South University

Liang Hu

Central South University

Wei Sun

Central South University

Dajun Zhang

Xiangdong Optoelectronics Science and Technology Park

\section{Research Article}

Keywords: Manganese slag, Porous ceramics, Silica carbon, Silicate tailings

Posted Date: June 2nd, 2021

DOl: https://doi.org/10.21203/rs.3.rs-577282/v1

License: (9) (i) This work is licensed under a Creative Commons Attribution 4.0 International License.

Read Full License 
Utilization of both electronical manganese slag and silicate tailings as raw materials for fabrication of cost-effective porous ceramics

Hongfu Lin ${ }^{\mathrm{a}, 1}$, Mengke Li ${ }^{\mathrm{a}, 1}$, Zhiguo He ${ }^{\mathrm{a}, \mathrm{c}, \mathrm{d}^{*}}$, Hui Zhong ${ }^{\mathrm{b},{ }^{*}}$, Liang Hu $\mathrm{H}^{\mathrm{a}}$, Wei Sun ${ }^{\mathrm{a}}$, Dajun Zhang $^{\mathrm{d}}$

a School of Minerals Processing and Bioengineering, Key Laboratory of Biohydrometallurgy of Ministry of Education, Central South University, Changsha 410083, China

${ }^{\mathrm{b}}$ School of Life Science, Central South University, Changsha, 410012, China

${ }^{\mathrm{c}}$ Faculty of Materials Metallurgy \& Chemistry, Jiangxi University of Science \& Technology, Ganzhou, Jiangxi, 341000, China

${ }^{\mathrm{d}}$ Xiangdong Optoelectronics Science \& Technology Park, Pingxiang, Jiangxi, 337000, China

*Corresponding authors: Zhiguo-He, e-mail: zghe@csu.edu.cn; Hui-Zhong, e-mail: hmmzhjj@csu.edu.cn

${ }^{1}$ These authors contributed equally to this work. 


\begin{abstract}
Herein, porous wollastonite ceramics with high porosity and low density were successfully fabricated with silicate tailings and electrolytic manganese slag (MS) as primary raw materials. The influences of calcination temperature, $\mathrm{SiC}$ and $\mathrm{MS}$ addition amounts on porosity, water adsorption, pore distribution, bulk density and bending strength were systematically studied. The results showed that $0.4 \mathrm{wt} \%$ of SiC was optimal for the ceramic foaming at the sintering temperature of $1140{ }^{\circ} \mathrm{C}$. The addition of MS promoted the foaming of ceramic matrix at low temperature. The porosity of ceramics reduced from $78.4 \%$ to $63.7 \%$, bulk density elevated from 0.96 to $1.13 \mathrm{~g} / \mathrm{cm}^{3}$, and bending strength increased from 8.43 to $11.22 \mathrm{MPa}$ as the MS increased from $8.33 \mathrm{wt} \%$ to $46.67 \mathrm{wt} \%$. Moreover, the best corrosion resistance performance reached to $99.55 \%$ with $8.33 \mathrm{wt} \% \mathrm{MS}$ content and sintering temperature of $1160{ }^{\circ} \mathrm{C}$. This work is of significance for the solid waste utilization.
\end{abstract}

Keyword: Manganese slag; Porous ceramics; Silica carbon; Silicate tailings 


\section{Introduction}

Closed porous ceramics (CPCs) were identified as excellent potential materials in the field of architecture because they have outstanding mechanical capacity, thermal shock resistance and chemical stability [1-3]. The application of CPCs as construction materials is of great significance to energy conservation and environmental protection. However, the raw materials used for CPCs preparation mainly include pure $\mathrm{Al}_{2} \mathrm{O}_{3}$, $\mathrm{SiO}_{2}, \mathrm{ZrO}_{2}$, clay and kaolin $[4,5]$. In addition, most of the reported CPCs were prepared at the sintering temperature higher than $1200{ }^{\circ} \mathrm{C}$, but high temperature means more energy consumed. As a result, the complicated and expensive (both raw material and sintering cost) fabrication process have limited the large-scale application of the porous ceramics $[6]$.

Industrial solid wastes (ISWs) including tailings and metallurgical slags have occupied large amount of land and polluted the soil and groundwater, arousing great attentions in recent years [7-10]. Tailings and/or metallurgical slags always contain abundant active silica (aluminum) oxygen tetrahedrons, metal oxides and other useful components. Therefore, the safe utilization of tailings and metallurgical slags as alternative raw materials of CPCs are of great concerns [11]. Up to now, many researchers have found that CPCs with better performance could be obtained by applying different industrial solid wastes as raw materials and supplementing appropriate additive components to adjust the contents of variant chemicals ) [12-15]. However, the solid wastes used for porous ceramic preparation are still limited to fly ash, coal gangue, steel slag and red mud. Moreover, the strength of as-prepared 
ceramics and the proportion of added solid wastes was relatively low, which impedes the large-scale consumption of solid wastes. Therefore, it is very important to prepare porous ceramics with high proportion of solid wastes at relatively low sintering temperature.

Electrolytic manganese slag (MS), the by-product of electrolytic manganese industry with an output of 11 million tons per year in China [16], is usually deposited in the open air. If it is not handled properly, the heavy metals are easily leached out and then infiltrate into the ground. As a consequence, the treatment of MS has become the biggest obstacle to the development of electrolytic manganese industry in China. Due to the diversity of manganese production technology, the main compositions of MS are slightly different, but they generally include $\mathrm{SiO}_{2}, \mathrm{Al}_{2} \mathrm{O}_{3}$, and various $\mathrm{Ca}, \mathrm{Fe}$ and Mn oxides or sulfides, indicating that the MS could also be applied as pristine materials for porous ceramics fabrication. Besides, the interaction among variant components might be benefit to construct a strong-strength CPCs even at lower sintering temperature. However, there was no report on the fabrication of $\mathrm{CPCs}$ employing MS as raw materials, and the possibility and superiority of MS-based ceramics need to be fully recognized and deeply explored.

In this work, both MS and silicate tailings (ST) were used as the primary material in CPCs production, between which ST, a typical industrial tailing, was used as silica source. Meanwhile, $\mathrm{SiC}$ was chosen as pore-forming agent, and bentonite (BT) and potash feldspar (PF) were employed as additives. The influences of the $\mathrm{SiC}$, calcination temperature and proportion of MS on the ceramics properties, including 
phase evolution, bulk density, thermal conductivity, bending strength and corrosion resistance were systematically studied. Finally, the possible reactions occurred during the sintering process were also explored.

\section{Experimental Method}

\subsection{Materials}

ST were got from Guangdong, China. The MS was provided by Xiangtan Electrochemical Technology Co., Ltd. China. The bentonite (BT) was got from Henan, China. Potash feldspar (PF) used in this experiment was got from Jiangsu Province, China. Silicon carbide $(\mathrm{SiC})$, sodium carbonate $\left(\mathrm{NaCO}_{3}\right)$ and magnesium oxide $(\mathrm{MgO})$ were purchased from Aladdin Chemical Reagent Co., Ltd (Shanghai, China).

\subsection{Ceramic fabrication}

The powder mixture consisting of $66.67 \mathrm{wt} \% \mathrm{ST}, 8.33 \mathrm{wt} \%, 41.7 \%$ or MS, 8.33 $\mathrm{wt} \%$ potash feldspar, $8.33 \mathrm{wt} \%$ bentonite, $4.17 \mathrm{wt} \% \mathrm{MgO}, 4.17 \mathrm{wt} \% \mathrm{Na}_{2} \mathrm{CO}_{3}$ and 0.5 $\mathrm{wt} \% \mathrm{SiC}$ were ball-milled in water medium for $8 \mathrm{~h}$. The homogeneous slurry was dried at $80{ }^{\circ} \mathrm{C}$ for $10 \mathrm{~h}$, and the dried powders were ground and sieved through 250 mesh sieve. The obtained powders were then dry-pressing into regular shapes at $20 \mathrm{MPa}$ with a $50 \mathrm{~mm} \times 50 \mathrm{~mm}$ stainless steel mold. Then, the mixture would be used for further sintering process. The obtained samples were firstly sintered at $1000{ }^{\circ} \mathrm{C}$ for 30 $\min$ and then the temperature was increased to $1130^{\circ} \mathrm{C}$ for $30 \mathrm{~min}$ in a muffle furnace. The heating rate of $3{ }^{\circ} \mathrm{C} / \mathrm{min}$ was adopted during the whole calcination process from room temperature to $1000{ }^{\circ} \mathrm{C}$ and from $1000{ }^{\circ} \mathrm{C}$ to the set temperature.

\subsection{Characterization}


The material phases were measured by X-ray powder diffraction (XRD) in the range of $5^{\circ}$ to $80^{\circ}$. Morphologies and pore diameter were analyzed by a scanning electron microscope (SEM). The bending strengths of the samples (cut in $10 \mathrm{~mm} \times$ $10 \mathrm{~mm} \times 10 \mathrm{~mm}$ ) were determined using a servo dynamic test system. The thermogravimetric differential scanning calorimetry (TG/DSC) analysis was determined with a thermal analyzer. The thermal expansion coefficient of the ceramics was measured on a dilatometer.

The bulk density was obtained by dividing the mass with the volume, while the total porosity (P) was calculated via Eq. (1) [17] :

$$
\mathrm{P}(\%)=\frac{\rho}{\rho_{0}} \times 100 \%
$$

Where $\rho$ and $\rho_{0}$ means the bulk and powder density, respectively.

The apparent porosity (Q) was obtained from the boiling method according to the Eq. (2) [18]:

$$
\mathrm{Q}(\%)=\frac{m_{2}-m_{1}}{m_{2}-m_{3}} \times 100 \%
$$

Where $m_{1}, m_{2}$ and $m_{3}$ are the drying mass, saturated mass in air and water, respectively, in which the saturated mass in water was obtained by soaking the samples in boiling water for $5 \mathrm{~h}$ and then cooled to room temperature.

The water absorption (W) was determined by applying the following Eq. (3) [19].

$$
\mathrm{W}(\%)=\frac{m_{3}-m_{1}}{m_{1}} \times 100 \%
$$

The chemical stability of samples was determined in hydrochloric acid $(\mathrm{HCl})$ solution (the volume fraction was 18\%). The samples were soaked in $\mathrm{HCl}$ for $24 \mathrm{~h}$ at $\mathrm{pH}$ value of 2 . In each trial, five samples were used to obtain an average value. The 
corrosion resistance $(\mathrm{R})$ was obtained from the Eq. (4):

$$
\mathrm{R} \%=\mathrm{m}_{\mathrm{a}} / \mathrm{m}_{0} \times 100
$$

Where $m_{0}$ and $m_{a}$ denote the weight of dried samples before and after etch, respectively.

\section{Results and Discussion}

\subsection{Characterization of pristine materials}

The compositions of each material are displayed in Table 1. ST used in this study was mainly composed of $\mathrm{SiO}_{2}$ and $\mathrm{Al}_{2} \mathrm{O}_{3}$ (with the total content of $87.218 \mathrm{wt} \%$ ), and a small quantity of $\mathrm{Fe}_{2} \mathrm{O}_{3}, \mathrm{Na}_{2} \mathrm{O}$ and $\mathrm{K}_{2} \mathrm{O}$ also presented (9.2 wt\%). By contrast, much higher contents of $\mathrm{Fe}_{2} \mathrm{O}_{3}, \mathrm{MnO}_{2}$ and $\mathrm{CaO}$ existed in $\mathrm{MS}$, and their total content was up to $24.436 \mathrm{wt} \%$, which was higher than those of $\mathrm{SiO}_{2}$ and $\mathrm{Al}_{2} \mathrm{O}_{3}$ (with the total content of $10.803 \mathrm{wt} \%$ ). Besides, both $\mathrm{PF}$ and $\mathrm{BT}$ contained large proportion of $\mathrm{SiO}_{2}$ and $\mathrm{Al}_{2} \mathrm{O}_{3}$, and a considerable quantity of $\mathrm{Na}_{2} \mathrm{O}$ and $\mathrm{K}_{2} \mathrm{O}$. In general, $\mathrm{SiO}_{2}$ and $\mathrm{Al}_{2} \mathrm{O}_{3}$ are the main compositions of ceramics framework [11]. While alkaline oxide and alkaearth oxide could act as network modifiers which are beneficial to the calcination process of CPCs $[20,21]$. It should be noted that the contents of $\mathrm{MgO}$ were low in all raw materials, thus extra $\mathrm{MgO}$ was needed as flux to reduce the softening point of the ceramics. Fig. 1 shows the mineral phases of ST, MS and PF. The ST exhibited diverse phases including quartz $\left(\mathrm{SiO}_{2}, \mathrm{PDF} \# 46-1054\right)$, albite $\left(\mathrm{Na}\left(\mathrm{AlSi}_{3} \mathrm{O}_{8}\right), \mathrm{PDF} \# 76-1819\right)$, orthoclase $\left(\mathrm{K}_{4} \mathrm{Al}_{4} \mathrm{Si}_{12} \mathrm{O}_{32}, \mathrm{PDF} \# 71-0957\right)$ and muscovite $\left(\mathrm{KAl}_{2}\left(\mathrm{AlSi}_{3} \mathrm{O}_{10}\right)(\mathrm{OH})_{2}\right)$, PDF\#86-1384). The phases of MS consisted of quartz $\left(\mathrm{SiO}_{2}, \mathrm{PDF} \# 46-1054\right)$ and pyrochroite $\left(\mathrm{Mn}(\mathrm{OH})_{2}, \mathrm{PDF} \# 18-0787\right)$ crystalline structure. While the PF was mainly 
composed of microcline (K(AlSi $\left.\left.\mathrm{O}_{8}\right), \mathrm{PDF} \# 87-1792\right)$.

\subsection{Effect of sintering temperature}

The effect of calcination temperature on the phase evolution of the porous ceramics was studied by sintering samples at different temperatures in the range of $1000-1200{ }^{\circ} \mathrm{C}$ (Fig. 2). XRD results showed the main phases were quartz, bustamite and diopside at $1000^{\circ} \mathrm{C}$, accompanied with a small proportion of olivine and hematite. The hematite was stemmed from the raw material of MS, indicating $1000{ }^{\circ} \mathrm{C}$ was too low to make the raw matrix fully melted and recrystallized. With temperature elevated from $1120{ }^{\circ} \mathrm{C}$ to $1160{ }^{\circ} \mathrm{C}$, the major phases were transformed to wollastonite and olivine, and their peak intensities increased with the rise of temperature. When the sintering temperature was further elevated to $1200{ }^{\circ} \mathrm{C}$, the major phases remained unchanged. Fig. 3 displayed the corresponding SEM photographs of ceramics sintered at different temperatures. The average pore diameters of them were $0.83 \pm 0.25,0.95$ $\pm 0.17,1.44 \pm 0.36$ and $1.62 \pm 0.51 \mathrm{~mm}$ at the calcination temperatures of 1140,1160 1180 and $1200{ }^{\circ} \mathrm{C}$, respectively, which indicate that the average pore diameter increased with the increase of calcination temperature. The distribution of surface pore diameter at $1200{ }^{\circ} \mathrm{C}$ was obviously uneven. Meanwhile, it was found that with the temperature increasing, the wall thicknesses of pores decreased from 13.01 to 11.44 , 8.52 and $6.78 \mu \mathrm{m}$, respectively. This phenomenon could be explained by the fact that as temperature increased, the viscosity of raw matrix decreased and the bubbles expanded easily, which contributed to the increase of pore size $[8,21]$. However, the viscosity of mixtures could be impeded by the continuous increase of temperature, 
because the pore structure would be destroyed and numerous of connected pores would be generated. Thereby, small and uneven sizes pores were formed due to that gas caould easily escape from the connected holes. Additionally, the unwanted pores were also formed as the fluxing agent of sodium carbonate was decomposed.

Fig. $2 b$ shows the porosity and water adsorption of the samples. It was found the porosity of the samples was significantly raised from $66.1 \%$ to $89.2 \%$. Meanwhile, the water adsorption slightly rose from $2.68 \%$ to $4.65 \%$. As mentioned above, the porosity was mainly related to the quantity and the size of holes. The viscosity of glass phase reduced with the elevation of calcination temperature, resulting in the connection of small pores to form large ones [17]. The water absorption was directly correlated with open pores on the surface. At high temperature, the generation of glass phase content leaded to the hole expansion, which was favorable for the water absorption. Fig. 2c shows that the bulk density and bending strength had the opposite tendency of porosity, which decreased continuously with temperature increasing. Specifically, the bulk density was declined from $1.07 \mathrm{~g} / \mathrm{cm}^{3}$ to $0.56 \mathrm{~g} / \mathrm{cm}^{3}$ with temperature increasing. Accordingly, the minimum and the maximum bending strengths were 9.97 Mpa and 6.96 Mpa, respectively. These results are consistent with some previously reported studies [2]. It was reported that the bulk density was mainly dependent on the powder itself and pore structure [22]. In this study, the high value of bulk density might be ascribed by 1) the high content of iron and manganese oxides in the raw materials; 2) the formation of large pores with the rise of sintering temperature; and 3) the volume of samples expanded. 
The thermal conductivity of ceramics is shown in Fig. 2d. It was observed that the thermal conductivity decreased as temperature was elevated, with a minimum thermal conductivity of $0.2 \mathrm{~W} / \mathrm{m} \cdot \mathrm{K}$ at $1200^{\circ} \mathrm{C}$. The reduction of thermal conductivity was resulted from the rise of porosity at high temperature. In CPCs, the heat conduction is comprised with both solid and gas phase conduction. The large amount of the gas phase was not conducive to the thermal conductivity. When the heat flow passed through the ceramic bodies, high porosity at high temperature caused the reduction of the thermal conductivity of the ceramics [23]. The composites with thermal conductivity lower than $0.25 \mathrm{~W} /(\mathrm{m} \cdot \mathrm{K})$ could be considered as thermal insulation, therefore, the porous ceramics fabricated in this study could be the candidate of energy-saving building materials.

\subsection{Effect of MS addition amount}

Fig. 4 presents the influence of MS addition on the phase composition, morphology and other characteristics of porous ceramics sintered at $1140{ }^{\circ} \mathrm{C}$. In the absence of MS, the main phases of porous ceramics were wollastonite and forsterite. After the addition of MS, the contents of wollastonite and forsterite decreased, and the intensities of Mn-related phases (Nchwaningite) increased, accompanied by the emerging of Fe-based phases (Rozenite and Marcasite). With the proportion of MS increased from $8.3 \%$ to $41.67 \%$, there were no significant differences in the major phases, but the peak intensities of $\mathrm{Fe}$ and Mn-containing phases were enhanced, indicating the liquid phase has been formed while MS was involved into the complete recrystallization [24]. Meanwhile, with the MS content increased, the porosity and 
water adsorption of the samples fell from $78.4 \%$ to $63.7 \%$ and $3.35 \%$ to $1.73 \%$, respectively. However, the foamed ceramics could not be formed at $1140{ }^{\circ} \mathrm{C}$ when no MS was added, indicating that there were intrinsic substances in MS that could accelerate the generation of liquid phase. The higher proportion of MS was added, the more liquid phase was formed in the ceramic. Correspondingly, the bulk density and bending strength of various samples increased with the rise of MS amount. The maximum values of bulk density and bending strength were $1.13 \mathrm{~g} / \mathrm{cm}^{3}$ and $11.22 \mathrm{Mpa}$, respectively, when $41.67 \%$ of MS was added, and the minimum values were 0.96 $\mathrm{g} / \mathrm{cm}^{3}$ and $8.43 \mathrm{Mpa}$, respectively, when $8.33 \mathrm{wt} \%$ of MS was added. In other words, higher proportion of MS contributed to higher bending strength of the samples at the same calcination temperature. The raw manganese slag was rich in $\mathrm{CaSO}_{4}$, which could react with the tailing particles to produce a network structure in the sample to increase the bending strength. It should be mentioned that the color of foam ceramics kept deepening and more uneven pores appeared with the increase of MS content, and the appropriate pre-treatment could avoid this embarrassment.

The chemical stability of foamed ceramics is a crucial parameter if they would be applied as building materials. The corrosion resistance of various ceramics in $\mathrm{HCl}$ is displayed in Fig. 4d. The corrosion resistance of ceramics raised at first and reduced with the sintering temperature increase. The greatest mass loss $(9.4 \%)$ was occurred at $1000{ }^{\circ} \mathrm{C}$, which should be because the specimen has not vitrified and therefore was prone to be acidic corrosion at this temperature. The corrosion resistance became better as the sintering temperature rose to $1160^{\circ} \mathrm{C}$ ascribed by the increased proportion 
of glass phase. There are few glass phases at low temperature, and solid substrates like metal oxides could be etched by acid. The growing glass phase sintered at high temperature could inhibit the interaction between solid substrate and $\mathrm{HCl}$. However, when the calcination temperature rose to $1200^{\circ} \mathrm{C}$, the corrosion resistance became poor. This might be resulted from the large pores, which brought about sufficient reaction sites with $\mathrm{HCl}$. In this study, the ceramics prepared at $1160{ }^{\circ} \mathrm{C}$ possessed the superior corrosion resistance property with a rate of $99.55 \%$. Besides, it was found that the ceramics became sensitive to the changes of calcination temperature with the increase of MS content [25]. The reason may be due to that the large amount of $\mathrm{Ca}$ in the raw matrix caused the rapid decrease in viscosity of the liquid phase with the temperature increase, leading to the apparent difference in embryo body shrinkage $[26]$.

\subsection{Effect of SiC addition amount}

The XRD patterns of the foamed ceramics with various $\mathrm{SiC}$ contents calcinated at $1140{ }^{\circ} \mathrm{C}$ are provided in Fig. 5a. The main crystalline phases were wollastonite (ICDD\# 00-006-0258) and forsterite (ICDD\# 00-006-0258). With the rise of SiC amount, the intensities of major phases were enhanced, and the phases of nchwaningite (ICDD\# 00-006-0258), rozenite (ICDD\# 00-006-0258) and marcasite (ICDD\# 00006-0258) appeared, the intensities of which increased gradually with the increase of $\mathrm{SiC}$ amount. When the percentage of $\mathrm{SiC}$ reached to $0.5 \mathrm{wt} \%$, the phase of picromerite (ICDD\# 00-006-0258) emerged. All these phases could not be detected in the raw materials, indicating that the new phases were formed from recrystallization at high 
temperature condition. During the sintering process, the $\mathrm{SiO}_{2}$ could be formed by the oxidation of $\mathrm{SiC}$, which then reacted with $\mathrm{Al}_{2} \mathrm{O}_{3}, \mathrm{CaO}$ and other alkali metals to form new phases like rozenite, marcasite and picromerite [27].

Several properties of the ceramics were evaluated to study the influence of $\mathrm{SiC}$ content. As shown in Fig. 5b, the porosity increased significantly from $4.39 \%$ to $81.3 \%$, and the water adsorption ratio was also correspondingly elevated from 5.14\% to $73.22 \%$ with the increase of $\mathrm{SiC}$ content. With the porosity increasing, the bulk density fell from 3.74 to $0.68 \mathrm{~g} / \mathrm{m}^{3}$ accordingly. Fig. $5 \mathrm{c}$ displayed the bending strength of the ceramics with different $\mathrm{SiC}$ addition amounts. The bending strength of the samples reduced with the increase of $\mathrm{SiC}$ amounts, but still had 7.91 Mpa when the $\mathrm{SiC}$ content was $0.5 \mathrm{wt} \%$. The $0.4 \% \mathrm{SiC}$ exhibited a similar porosity but a higher bending strength than that of $0.5 \mathrm{wt} \% \mathrm{SiC}$. Generally, the rise of SiC content resulted in the increase of $\mathrm{CO}_{2}$ gas bubbles, which subsequently led to the growth of porosity [5]. However, this increasing tendency was limited, because the maximum porosity was determined by the gas capacity of the original matrix [28]. These results demonstrated that the gas capacity has arrived saturation at the $\mathrm{SiC}$ amount of $0.4 \mathrm{wt} \%$. There was no need to further increase the $\mathrm{SiC}$ content since the sample has reached the maximum porosity when $\mathrm{SiC}$ was $0.4 \mathrm{wt} \%$. Ma et al. reported that $15 \mathrm{wt} \%$ of $\mathrm{SiC}$ was required to obtain $51.2 \%$ porosity when preparing porous mullite ceramics with fly ash [29], while 35.37 $\mathrm{wt} \%$ of $\mathrm{SiC}$ was needed to prepared silica/mullite porous ceramic using silicon kerf waste as raw material with the maximum porosity of $84.1 \%$ [30]. Nevertheless, the low demand for SiC used in our study was in according with the concept of "economic 
foamed-ceramics" because the price of $\mathrm{SiC}$ is usually expensive.

3.5 Possible reactions occurred in preparation process

It could be concluded from the above results that four parameters ( $\mathrm{SiC}$ and $\mathrm{MS}$ contents, sintering temperature and PF amounts) all have affected the physicochemical properties of ceramics. During the sintering process, multiple stages were involved, including the decomposition of raw materials, primary crystallization and secondary crystallization. Thermodynamics can uncover the probable variation in the components of the samples before and after having been sintered at different stages. The TG/DSC analysis of the foamed ceramics was applied to reveal the possible changes in ceramics phases at different stages (Fig. 6). The obvious exothermic peak located at $136{ }^{\circ} \mathrm{C}$ was related to the dehydration of $\mathrm{CaSO}_{4} \cdot 2 \mathrm{H}_{2} \mathrm{O}$ in MS (Eq. (1)). Since the formation of liquid phase and the crystallization during the sintering process are endothermic reactions, several endothermic peaks observed between $300{ }^{\circ} \mathrm{C}$ and $650{ }^{\circ} \mathrm{C}$ might be related to the dehydration of aluminum hydroxide (Eq. (2)). Besides, the exothermic peak appeared at $855^{\circ} \mathrm{C}$ was corresponded to the decomposition of $\mathrm{CaSO}_{4}$ and the formation of $\mathrm{CaO}$ (Eq. (3)), these processes of which were beneficial to the formation of wollastonite $\left(\mathrm{Ca}_{3}\left(\mathrm{Si}_{3} \mathrm{O}_{9}\right)\right)$. Furthermore, another obvious exothermic peak at $999^{\circ} \mathrm{C}$ was belonged to the oxidation of $\mathrm{SiC}$, which was accompanied by the formation of $\mathrm{SiO}_{2}$ and $\mathrm{CO}_{2}$ (Eq. (4)). Therefore, a slow heating rate and a certain retention time was required at $\sim 1000{ }^{\circ} \mathrm{C}$ to ensure the complete reaction among various components in the melt and to make ceramic fully foamed. It should be mentioned that with the rise of calcination temperature and MS addition amount, the intensity of 
diffraction peaks of Fe- and Mn-based phases increased slightly, which could be explained by that $\mathrm{Fe}_{2} \mathrm{O}_{3}$ and $\mathrm{Mn}_{2} \mathrm{O}_{3}$ were melted into the glass phase of silicon. Moreover, there exists a balance between $\mathrm{M}^{2+}, \mathrm{M}^{3+}(\mathrm{M}=\mathrm{Fe}$ and $\mathrm{Mn})$ and the dissolved oxygen in the fusion (Eq. (5)) at high temperature.

$\mathrm{CaSO}_{4} \cdot 2 \mathrm{H}_{2} \mathrm{O} \quad \rightarrow \quad \mathrm{CaSO}_{4}+\mathrm{O}_{2}$

$\begin{array}{llllll}\mathrm{CaSO}_{4} & \rightarrow & \mathrm{CaO} & \mathrm{SO}_{2}\end{array}$

$\mathrm{Al}(\mathrm{OH})_{3} \rightarrow \mathrm{Al}_{2} \mathrm{O}_{3}+3 \mathrm{H}_{2} \mathrm{O}$

$\mathrm{SiC}+\mathrm{O}_{2} \rightarrow \mathrm{SiO}_{2}+\mathrm{CO}_{2}$

$\mathrm{M}^{3+}+2 \mathrm{O}^{2-} \leftrightarrow \mathrm{M}^{2+}+\mathrm{O}_{2}$

The lower sintering temperature for the porous ceramic prepared in this study than most previously reported solid waste based-ceramics might be ascribed by the following reasons: 1) the alkali metal oxides such as $\mathrm{K}_{2} \mathrm{O}$ and $\mathrm{Na}_{2} \mathrm{O}$ in tailings and $\mathrm{PF}$ have facilitated the calcination process by decreasing the softening temperature of the liquid phase, and therefore decreased the preparation temperature. In this study, PF was the main source of potassium oxide and sodium oxide in raw matrix. It was also reported that PF melt could dissolve part of tailings decomposition products and interact with both $\mathrm{Al}_{2} \mathrm{O}_{3}$ and $\mathrm{SiO}_{2}$ in the liquid phase. The particles filled by PF melt were not only beneficial to the densification of the green-body, but also promoted the nucleation and growth of new crystals, which endowed the ceramics with strong mechanical strength and excellent chemical stability; 2) the introduction of fluxing 
agent like $\mathrm{Na}_{2} \mathrm{CO}_{3}$ into the raw matrix could promote the particle diffusion when calcination, thus decreasing the firing temperature; and 3) base metal oxides participated into the reaction and were melt into the silica-rich glass phase, promoting the formation of a large amount of liquid phase and further reducing the firing temperature.

\section{Conclusion}

A series of porous ceramics were fabricated by applying MS and ST as the main materials and $\mathrm{SiC}$ as pore-forming agent, which were sintered at temperatures ranging from $1000{ }^{\circ} \mathrm{C}$ to $1200{ }^{\circ} \mathrm{C}$. Temperature, $\mathrm{MS}$ and $\mathrm{SiC}$ addition amount all have influenced the properties (including main phase, porosity, water adsorption ability, bulk density, bending strength, corrosion resistance) of as-prepared ceramics. $0.4 \mathrm{wt} \%$ of $\mathrm{SiC}$ was the most suitable content for ceramic foaming at $1140{ }^{\circ} \mathrm{C}$. The PF was conducive to the densification of the green-body and promoted the nucleation and growth of new crystals. While $\mathrm{Na}_{2} \mathrm{CO}_{3}$ acting as fluxing agent could promote the particle diffusion in the combustion process. Meanwhile, base metal oxides in MS involved in the melting process have facilitated the formation of liquid phase, further reducing the firing temperature of ceramics temperature.

\section{Acknowledgments}

This work was financially supported by the National Natural Science Foundation of China (No. 51774339). 


\section{References:}

[1] Man K, Zhu Q, Li L, Liu C, et al. Preparation and Performance of Ceramic Filter Material by Recovered Silicon Dioxide as Major Leached Component from Red Mud. Ceram. Int. 2017, 43 (10), 7565-7572.

[2] Bai Z, Li K, Ma X, et al. Preparation and Characterization of Molybdenum Tailings-Based Water Storage Material. Mater. Chem. Phys. 2019, 236 (April), 121791.

[3] Wang S, Wang H, Chen Z, et al. Fabrication and Characterization of Porous Cordierite Ceramics Prepared from Fly Ash and Natural Minerals. Ceram. Int. 2019, 45 (15), 18306-18314.

[4] Han F, Xu C, Wei W, et al. Corrosion Behaviors of Porous Reaction-Bonded Silicon Carbide Ceramics Incorporated with CaO. Ceram. Int. 2018, 44 (11), $12225-12232$.

[5] Xie M, Wu X, Liu J, et al. In-Situ Synthesis and Textural Evolution of the Novel Carbonaceous SiC/Mullite Aerogel via Polymer-Derived Ceramics Route. Ceram. Int. 2017, 43 (13), 9896-9905..

[6] Xing Z, Hu Y, Xiang D, et al. Porous SiC-Mullite Ceramics with High Flexural Strength and Gas Permeability Prepared from Photovoltaic Silicon Waste. Ceram. Int. 2020, 46 (1), 1236-1242.

[7] Xi C, Zhou J, Zheng F, et al. Conversion of Extracted Titanium Tailing and Waste Glass to Value-Added Porous Glass Ceramic with Improved Performances. J. Environ. Manage. 2020, 261 (April 2019), 110197. 
[8] Zong Y, Wan Q, Cang D, et al. Preparation of Anorthite-Based Porous Ceramics Using High-Alumina Fly Ash Microbeads and Steel Slag. Ceram. Int. 2019, 45 (17), 22445-22451.

[9] Zhao L, Li Y, Zhou Y, et al. Preparation of Novel Ceramics with High CaO Content from Steel Slag. Mater. Des. 2014, 64, 608-613.

[10] Abdel-Hameed S , Hamed I M , Erfan N A. Utilization of iron oxide bearing pellets waste for preparing hard and soft ferromagnetic glass ceramic. J. Adv. Ceram. 2014, 3(4): 259-268.

[11] Huang Q, Liu T, Zhang J, et al. Properties and Pore-Forming Mechanism of Silica Sand Tailing-Steel Slag-Coal Gangue Based Permeable Ceramics. Constr. Build. Mater. 2020, 253.

[12] Fu M, Liu J, Dong X, et al. Waste Recycling of Coal Fly Ash for Design of Highly Porous Whisker-Structured Mullite Ceramic Membranes. J. Eur. Ceram. Soc. 2019, 39 (16), 5320-5331.

[13] Chen R, Hei D, Li S, et al. Environment-Oriented Low-Cost $\mathrm{Al}_{2} \mathrm{O}_{3}$ Ceramics with Hierarchical Pore Structure Fabricated from SiC Solid Waste. Int. J. Appl. Ceram. Technol. 2020, 17 (1), 184-189.

[14] Shu Y, Pan Y, Wang L, et al. Synthesis of low-cost porous ceramic microspheres from waste gangue for dye adsorption. J. Adv. Ceram. 2018, 7(1): 30-40.

[15] Wang W, Chen W, Liu H. Recycling of Waste Red Mud for Fabrication of SiC/Mullite Composite Porous Ceramics. Ceram. Int. 2019, 45 (8), 9852-9857.

[16] Li M, Huang F, Hu L, et al. Efficient Activation of Peroxymonosulfate by a 
Novel Catalyst Prepared Directly from Electrolytic Manganese Slag for Degradation of Recalcitrant Organic Pollutes. Chem. Eng. J. 2020, 401 (June), 126085.

[17] Li Z, Li X, Tang Y, et al. Sintering behaviour and characterisation of low-cost ceramic foams from coal gangue and waste quartz sand. Adv. Appl. Ceram. 2016, $115,377-383$.

[18] Liu T, Li X, Guan L, et al. Low-Cost and Environment-Friendly Ceramic Foams Made from Lead-Zinc Mine Tailings and Red Mud: Foaming Mechanism, Physical, Mechanical and Chemical Properties. Ceram. Int. 2016, 42 (1), 17331739.

[19] Ouyang D, Zhuo Y, Hu L, et al. Research on the Adsorption Behavior of Heavy Metal Ions by Porous Material Prepared with Silicate Tailings. Minerals 2019, 9 (5).

[20] Hou Z, Cui B, Liu L, et al. Effect of the Different Additives on the Fabrication of Porous Kaolin-Based Mullite Ceramics. Ceram. Int. 2016, 42 (15), 1725417258.

[21] Zhao L, Li Y, Zhou Y, et al. Preparation of Novel Ceramics with High CaO Content from Steel Slag. Mater. Des. 2014, 64, 608-613.

[22] Ding L, Ning W, Wang Q, et al. Preparation and Characterization of GlassCeramic Foams from Blast Furnace Slag and Waste Glass. Mater. Lett. 2015, $141,327-329$.

[23] Zhou X, Zheng F, Li H, et al. An Environment-Friendly Thermal Insulation 
Material from Cotton Stalk Fibers. Energy Build. 2010, 42 (7), 1070-1074.

[24] Jiang L. Heat Treatment Parameters of Preparing Glass-Ceramic with Electrolytic Manganese Residue and Their Properties. J. Therm. Anal. Calorim. 2020, 140 (4), 1737-1744.

[25] Wang Z, Lyu X, Yao G, et al. Preparation of Ca-Si-Al-Mg Porous Ceramics by Co-Operation of Ca\&Mg-Contained Soda Residue and Altered Rock Gold Tailings. J. Clean. Prod. 2020, 262, 121345.

[26] Zhang J, Liu T, Huang Q, et al. Preparation, Properties Characterization and Structure Formation Mechanism of Silica Sand Tailings-Based Ceramic Materials. Mater. Chem. Phys. 2020, 255, 123611.

[27] Ren B, Li Y, Sang S, et al. Lightweight Design of Bauxite-SiC Composite Refractories as the Lining of Rotary Cement Kiln Using Alternative Fuels. Ceram. Int. 2017, 43 (14), 11048-11057.

[28] Dong Y, Hampshire S, Zhou J, et al. Recycling of Fly Ash for Preparing Porous Mullite Membrane Supports with Titania Addition. J. Hazard. Mater. 2010, 180 (1-3), 173-180.

[29] Ma B, Su C, Ren X, et al. Preparation and Properties of Porous Mullite Ceramics with High-Closed Porosity and High Strength from Fly Ash via Reaction Synthesis Process. J. Alloys Compd. 2019, 803, 981-991.

[30] Han Y, Zhou L, Liang Y, et al. Fabrication and Properties of Silica/Mullite Porous Ceramic by Foam-Gelcasting Process Using Silicon Kerf Waste as Raw Material. Mater. Chem. Phys. 2020, 240 (October 2019), 122248. 
Tables:

Table 1. The main chemicals composition (wt \%) of raw materials

\begin{tabular}{llllllllll}
\hline & $\mathrm{SiO}_{2}$ & $\mathrm{Al}_{2} \mathrm{O}_{3}$ & $\mathrm{Fe}_{2} \mathrm{O}_{3}$ & $\mathrm{MnO}_{2}$ & $\mathrm{CaO}$ & $\mathrm{Na}_{2} \mathrm{O}$ & $\mathrm{K}_{2} \mathrm{O}$ & $\mathrm{MgO}$ & $\mathrm{SO}_{3}$ \\
\hline $\mathrm{ST}$ & 73.123 & 14.095 & 2.273 & 0.060 & 0.035 & 1.885 & 5.042 & 0.317 & 0.205 \\
$\mathrm{MS}$ & 8.767 & 1.836 & 17.042 & 2.09 & 5.304 & 0.162 & 0.718 & 0.140 & 4.17 \\
$\mathrm{PF}$ & 70.123 & 16.785 & 0.212 & 0.034 & 0.834 & 5.436 & 5.241 & 0.125 & 0.058 \\
$\mathrm{BT}$ & 58.484 & 35.344 & 1.791 & 0.113 & 0.048 & 0.091 & 3.081 & 0.328 & 0.064 \\
\hline
\end{tabular}




\section{Figures:}

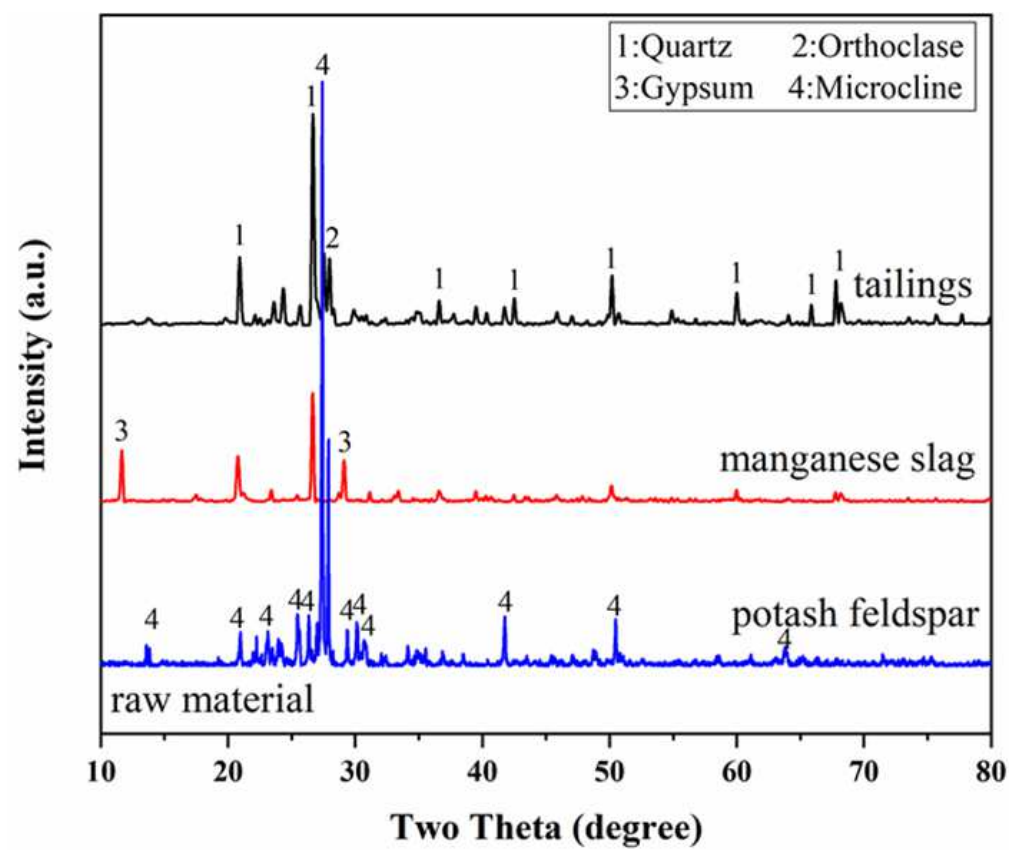

Fig. 1. The XRD patterns of raw materials. 

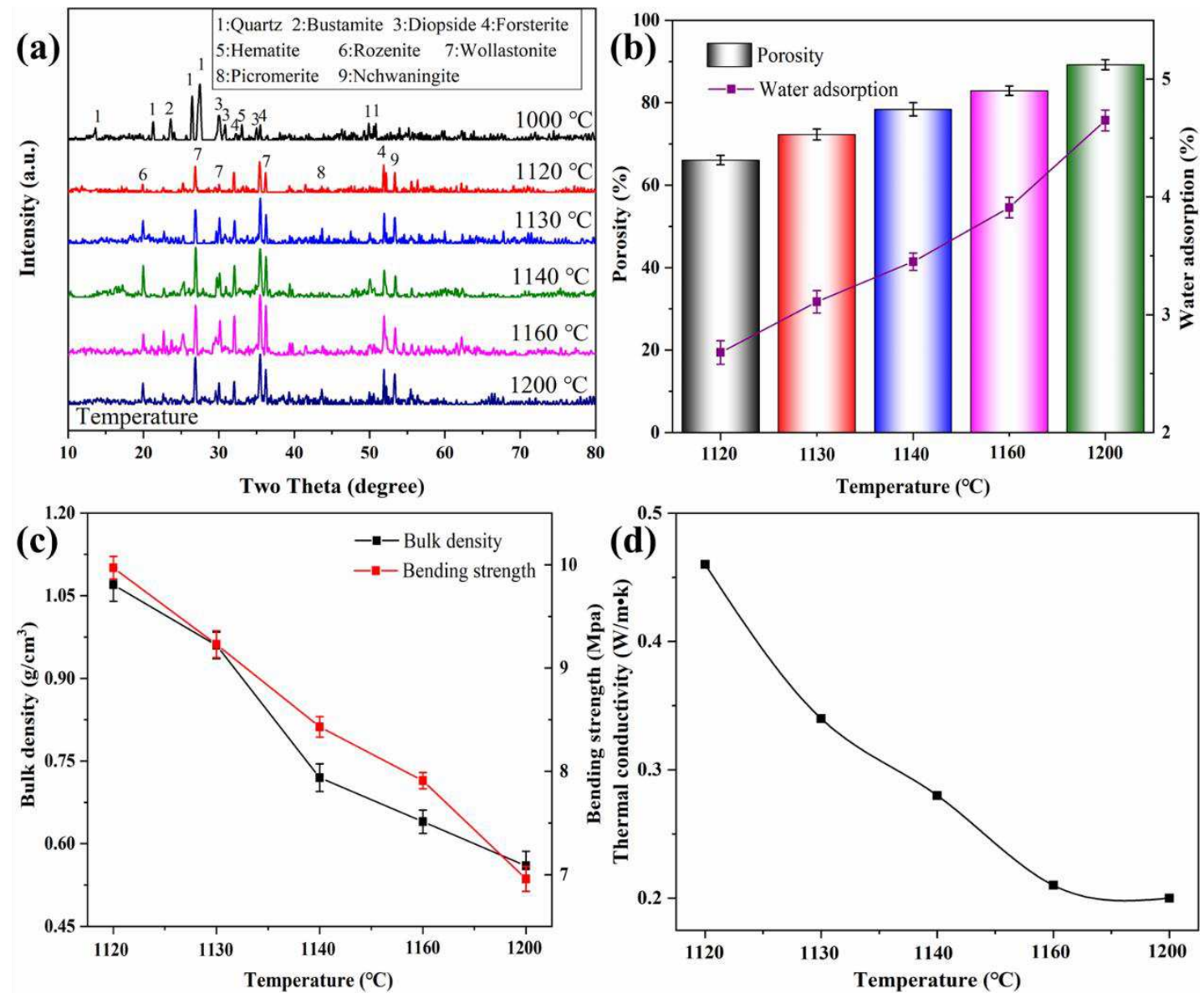

Fig. 2. The effects of temperature on XRD patterns (a), porosity and water adsorption

(b), bulk density and bending strength (c) and thermal conductivity (d) of ceramics. 

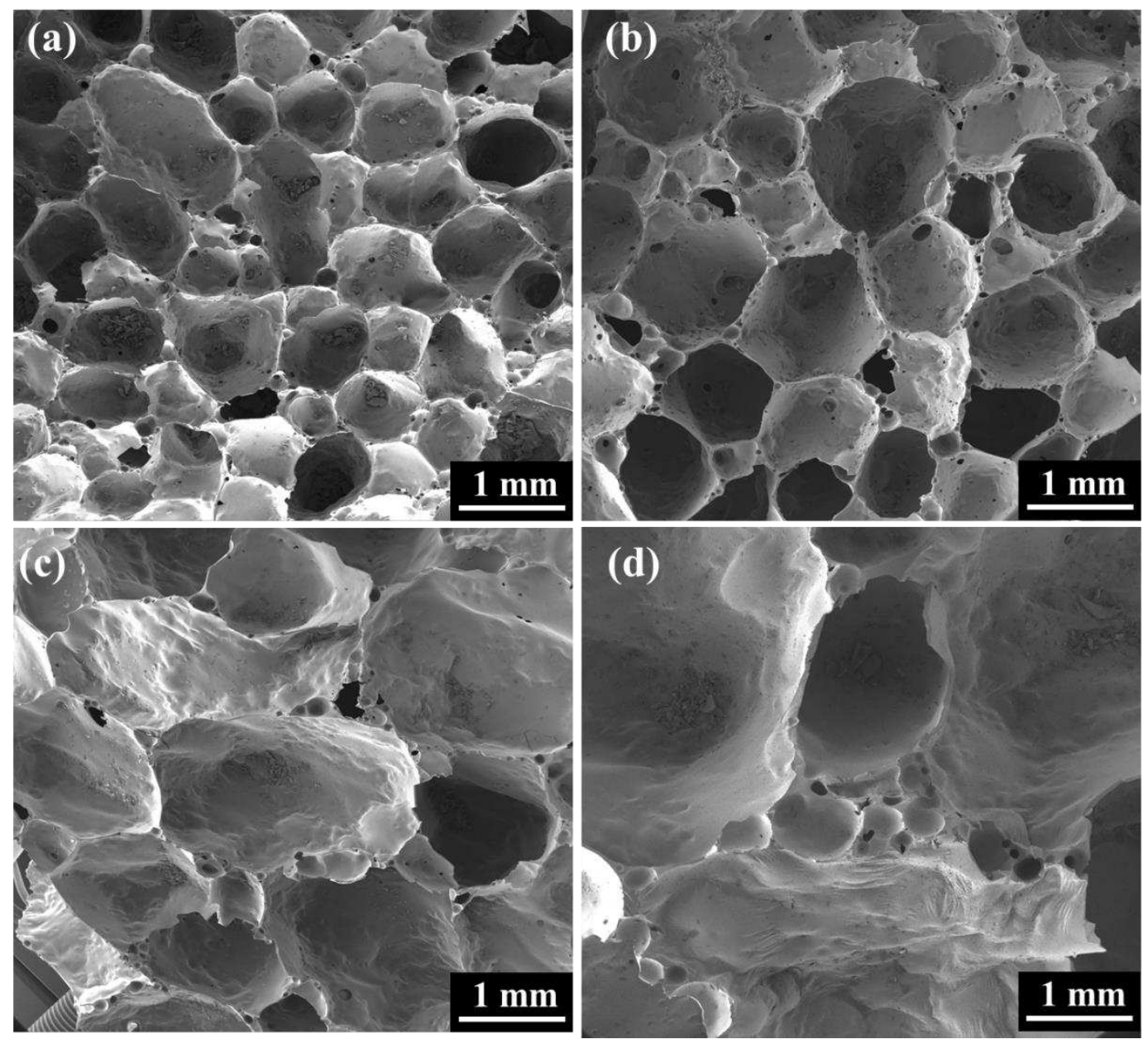

Fig. 3. Morphologies of ceramics prepared at (a) 1140, (b) 1160, (c) 1180 and (d) $1200{ }^{\circ} \mathrm{C}$. 

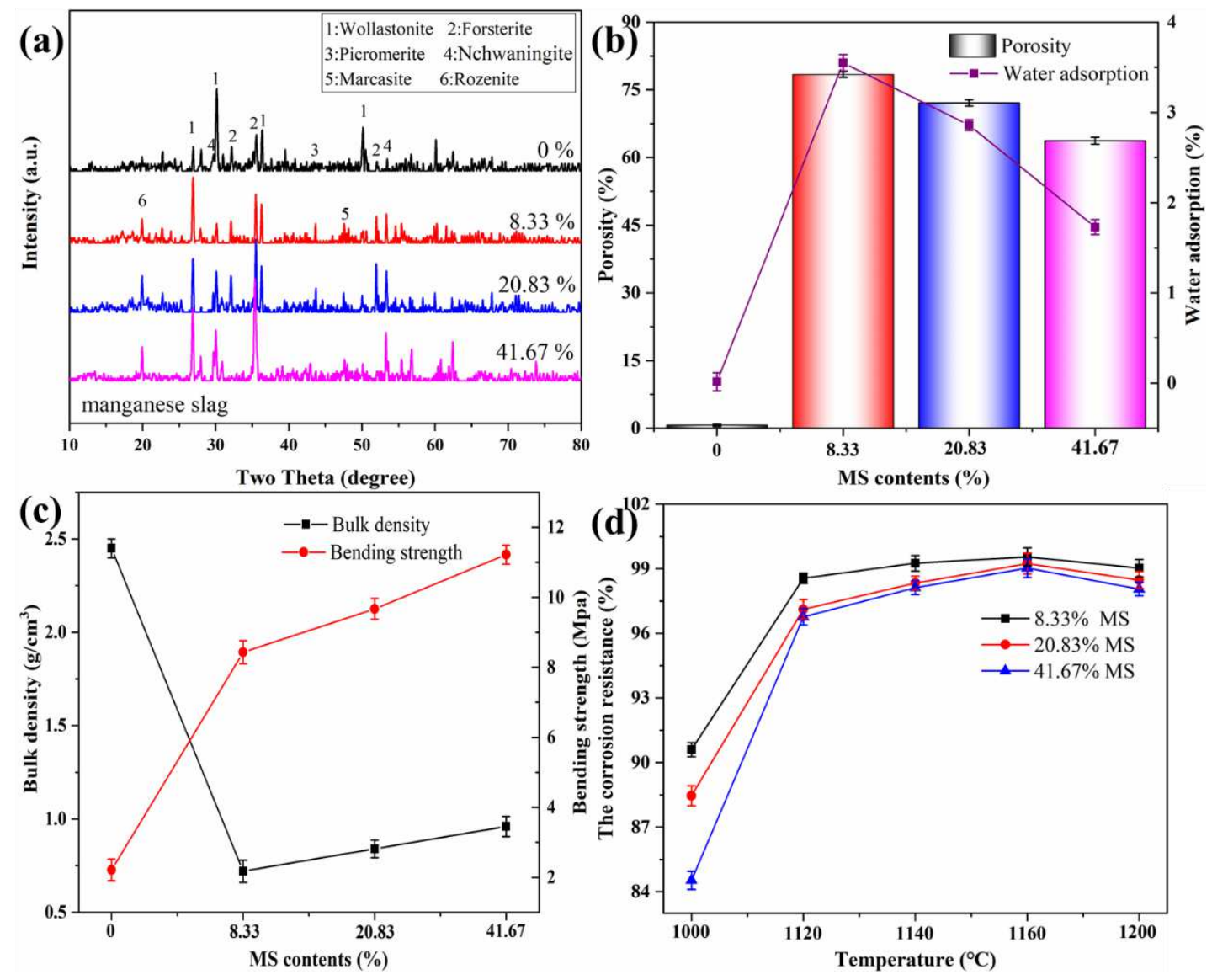

Fig. 4. The effects of MS amount on XRD patterns (a), porosity and water adsorption

(b), bulk density and bending strength (c) and corrosion resistance (d) of ceramics. 

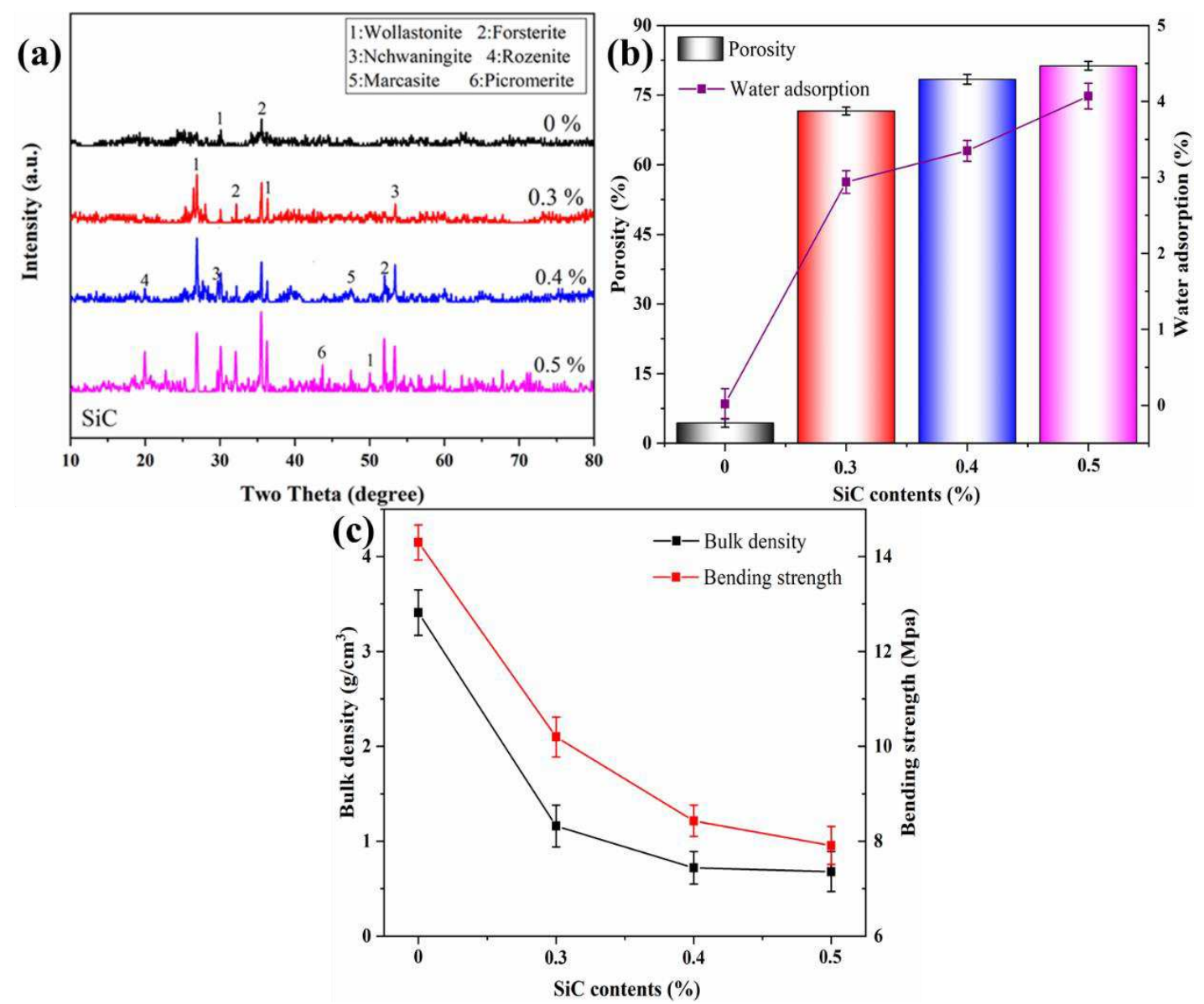

Fig. 5. The effect of SiC amount on XRD patterns (a), porosity and water adsorption

(b) and bulk density and bending strength (c). 


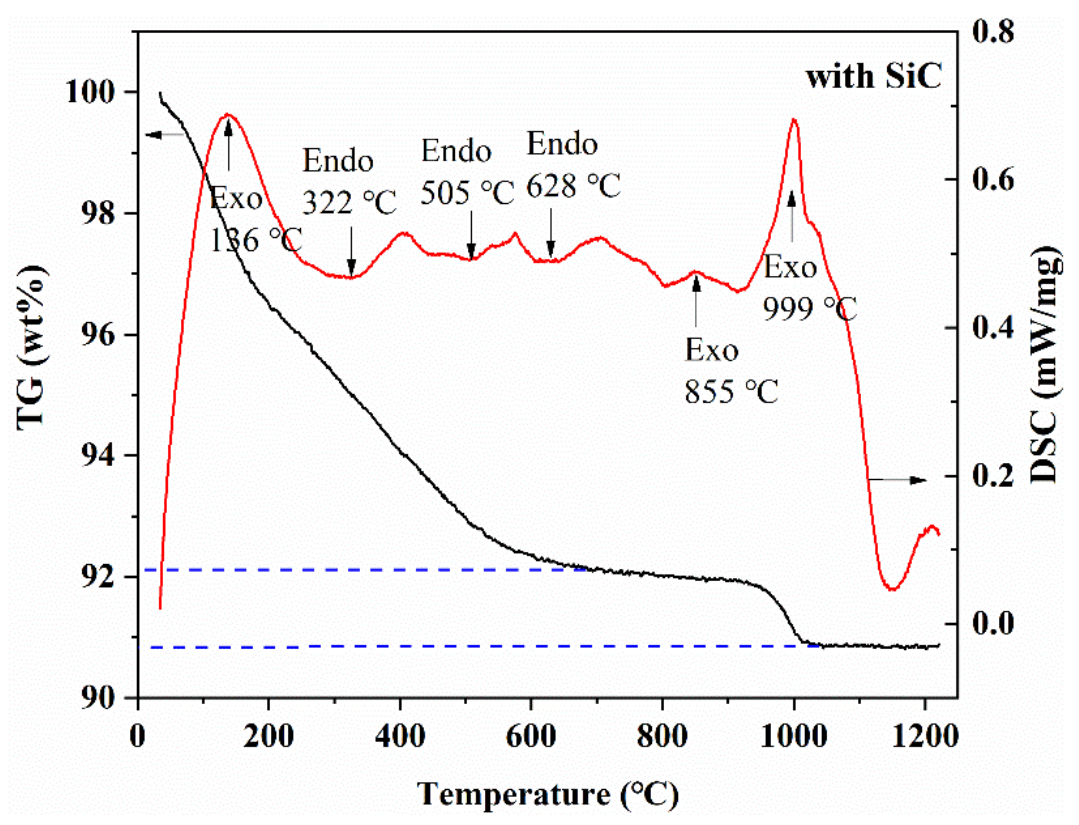

Fig. 6. TG/DSC analysis. 
Figures

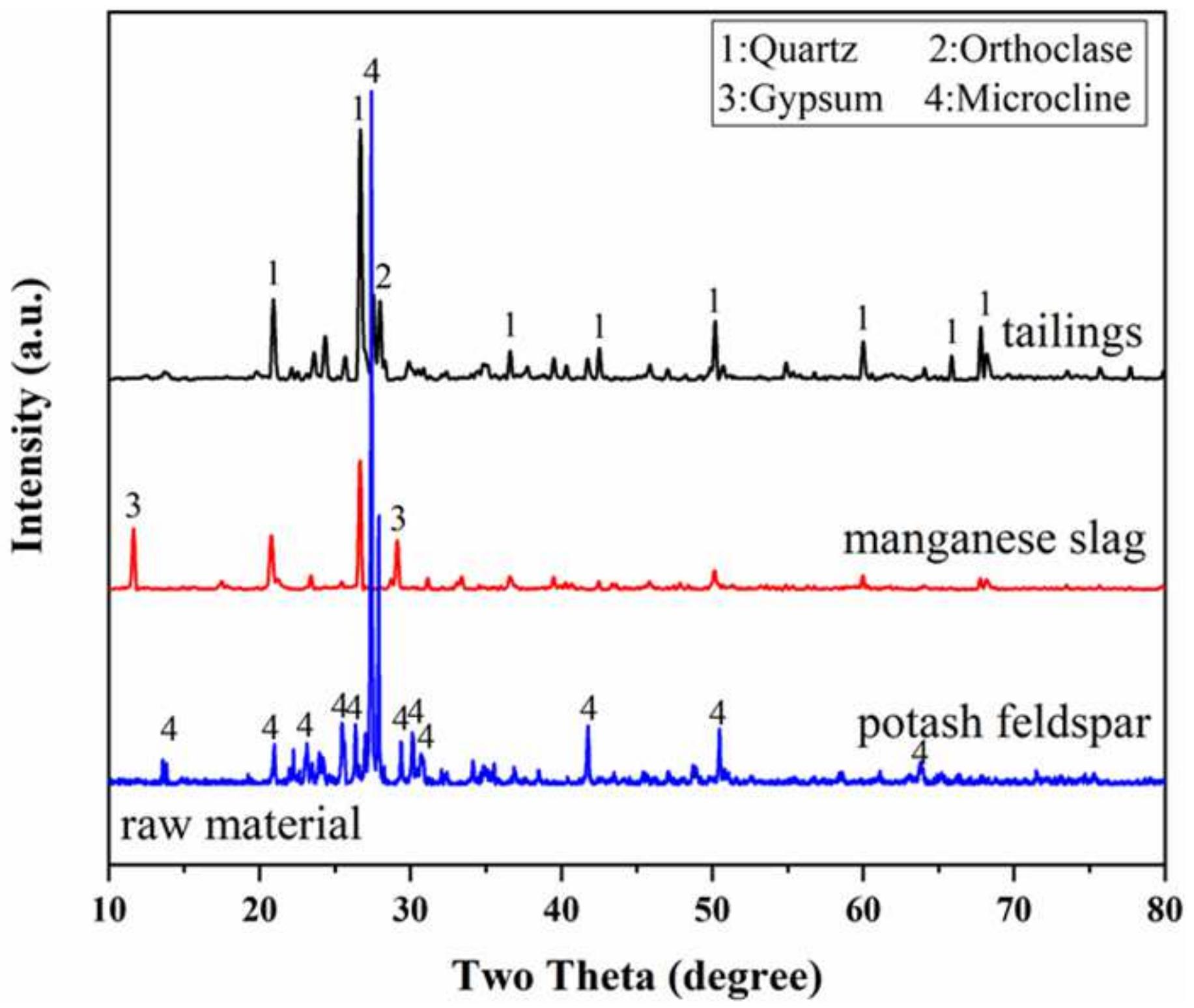

Figure 1

The XRD patterns of raw materials. 

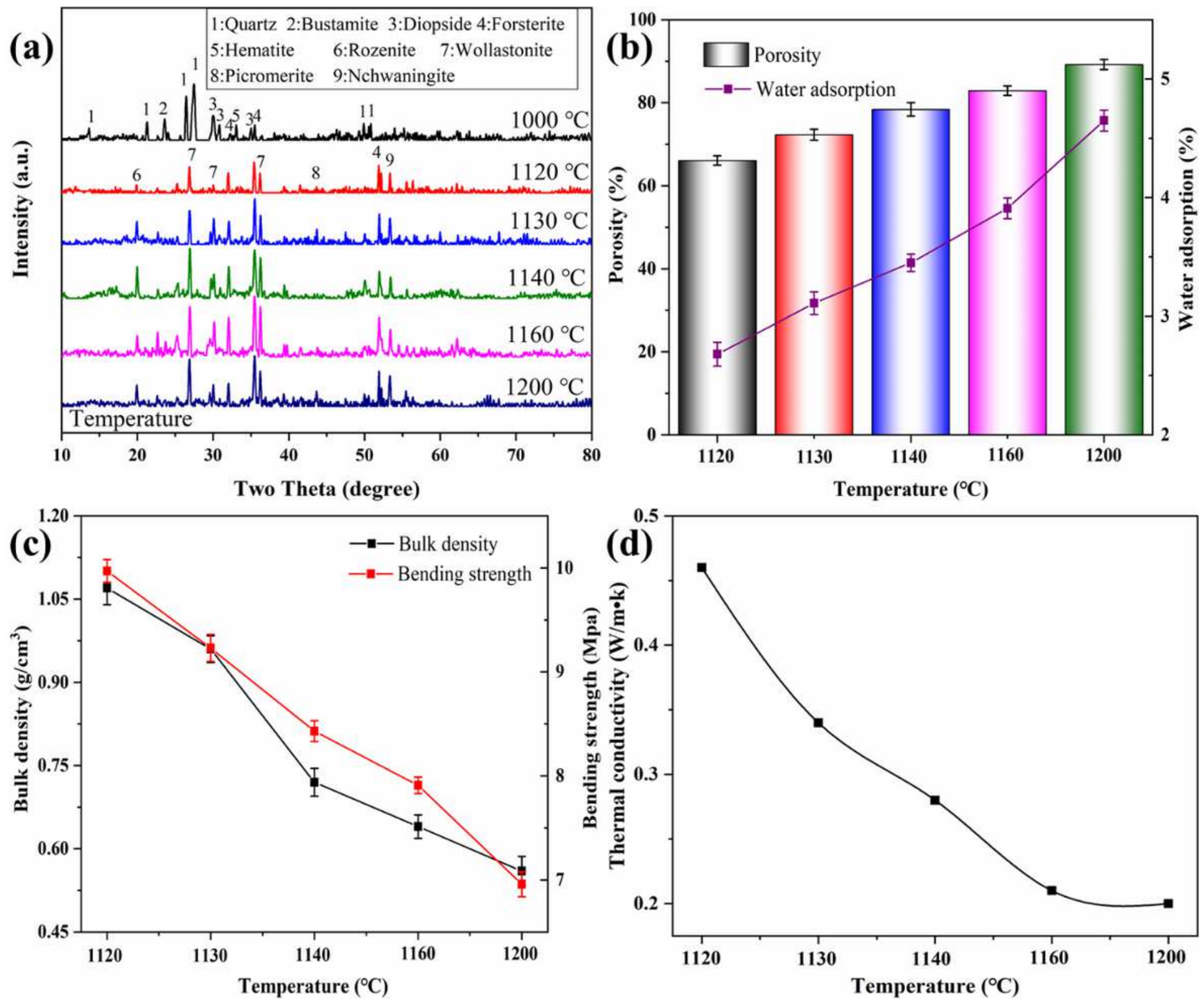

Figure 2

The effects of temperature on XRD patterns (a), porosity and water adsorption (b), bulk density and bending strength (c) and thermal conductivity (d) of ceramics. 

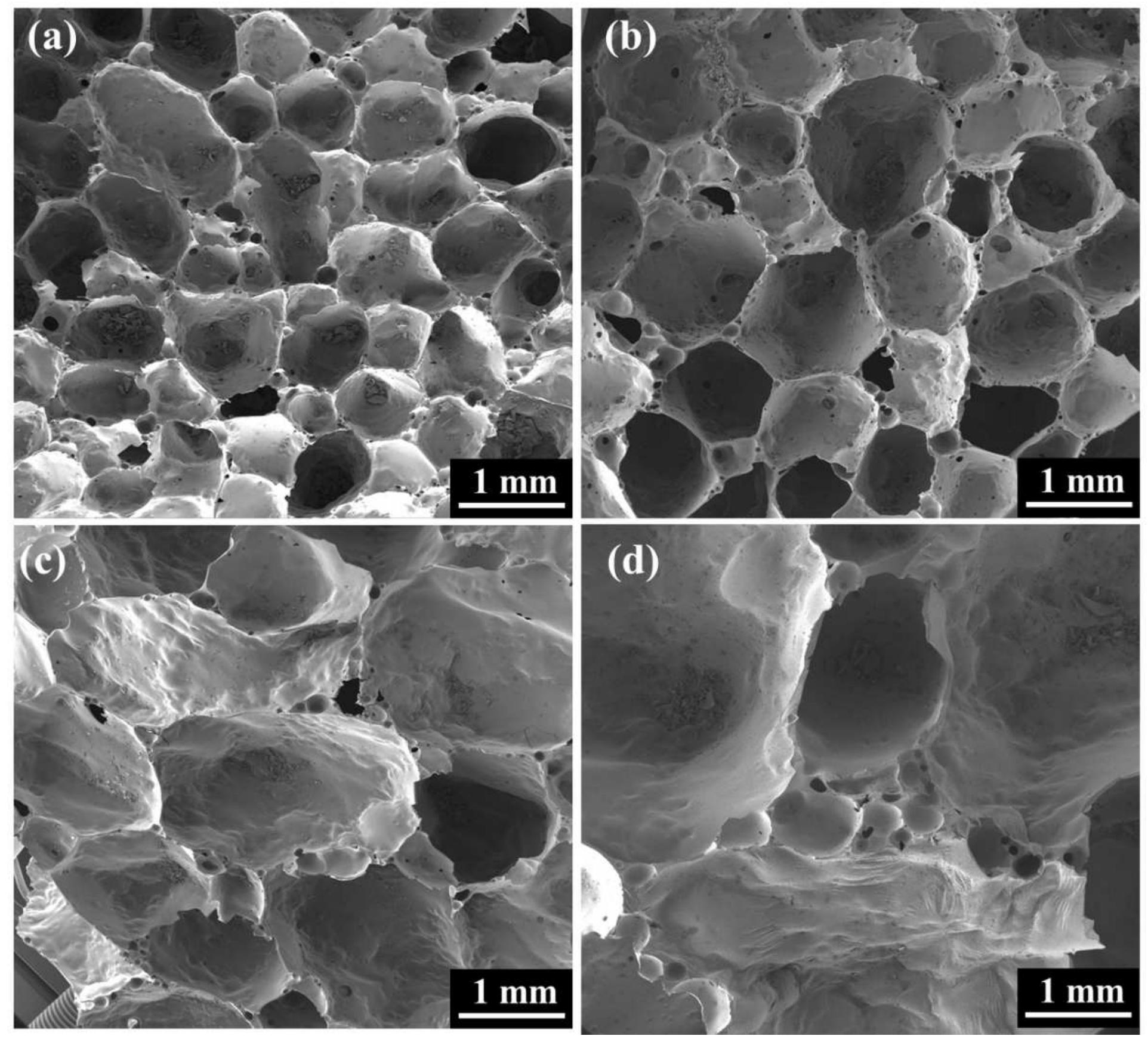

\section{Figure 3}

Morphologies of ceramics prepared at (a) 1140, (b) 1160, (c) 1180 and (d) $1200^{\circ} \mathrm{C}$. 

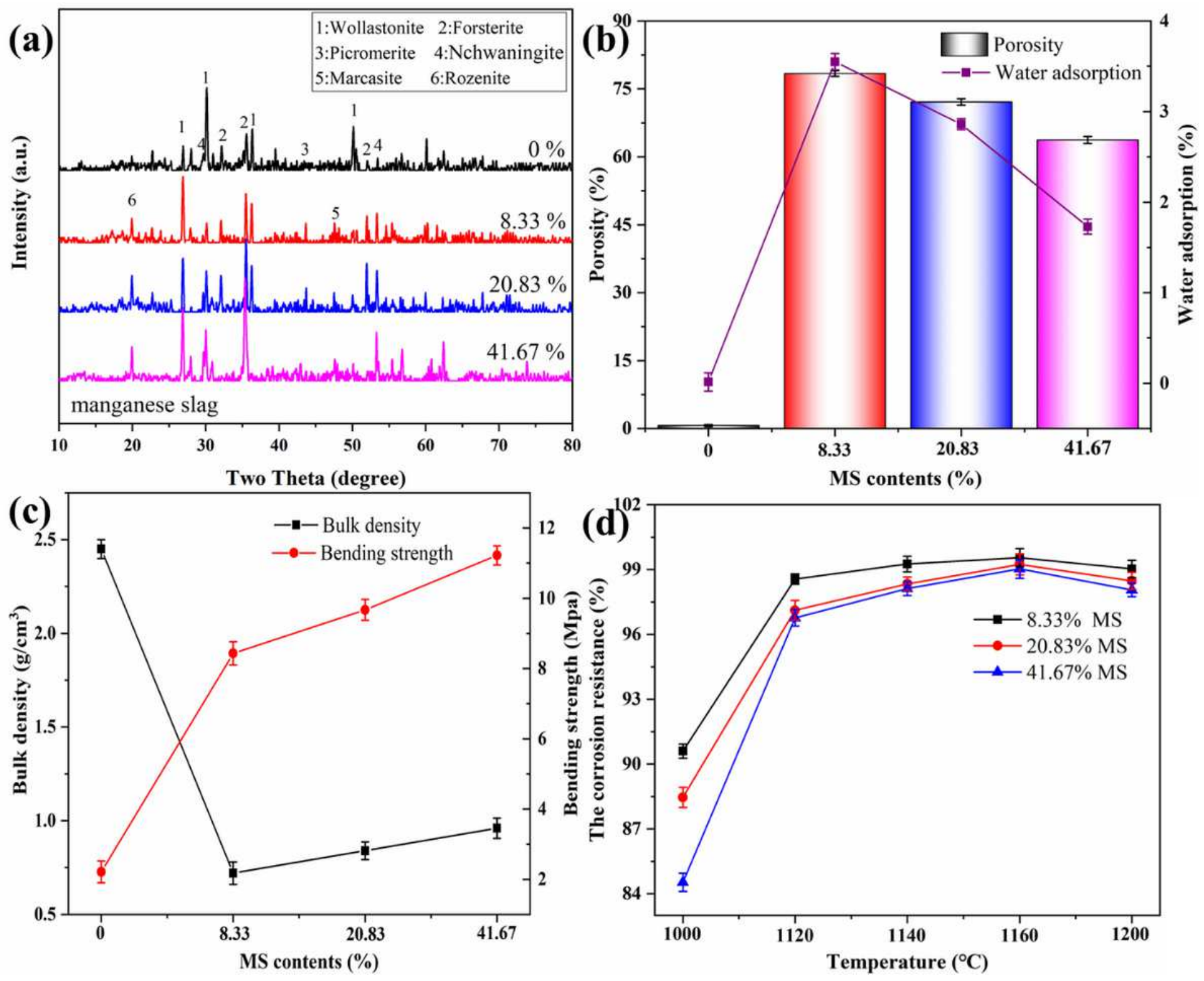

Figure 4

The effects of MS amount on XRD patterns (a), porosity and water adsorption (b), bulk density and bending strength (c) and corrosion resistance (d) of ceramics. 

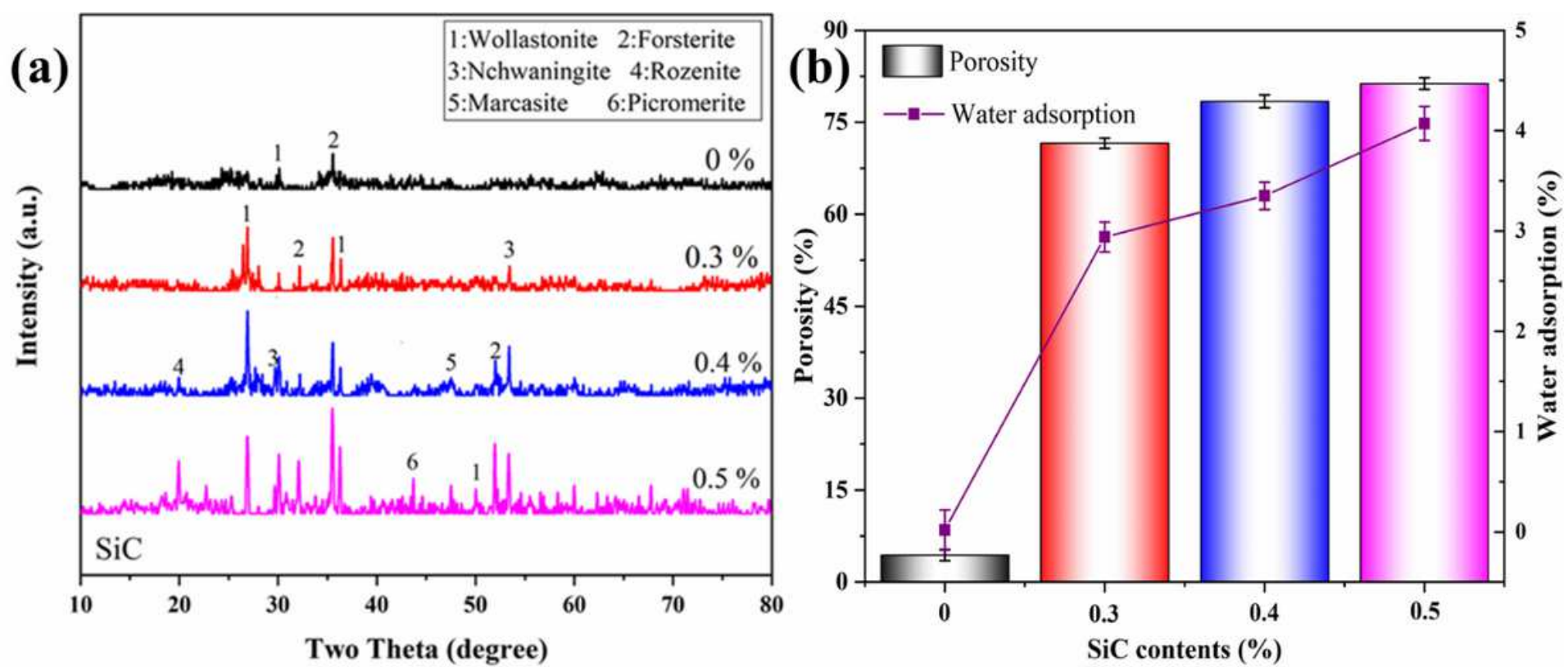

Two Theta (degree)

$\mathrm{SiC}$ contents $(\%)$

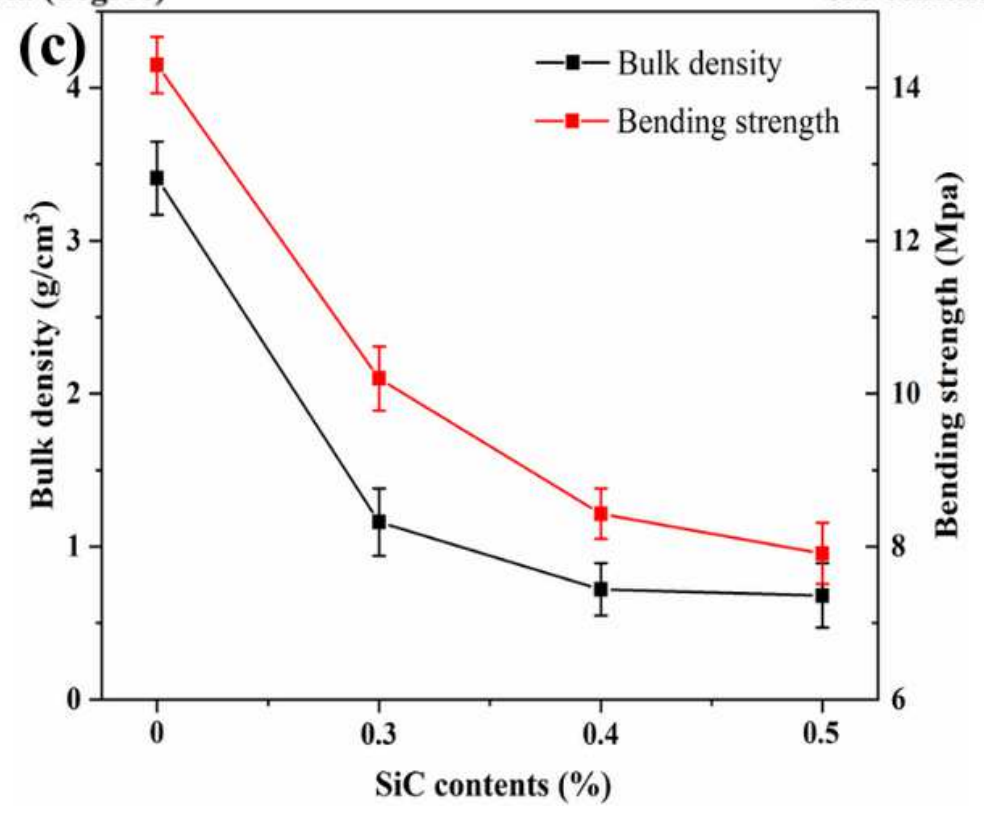

Figure 5

The effect of SiC amount on XRD patterns (a), porosity and water adsorption (b) and bulk density and bending strength (c). 


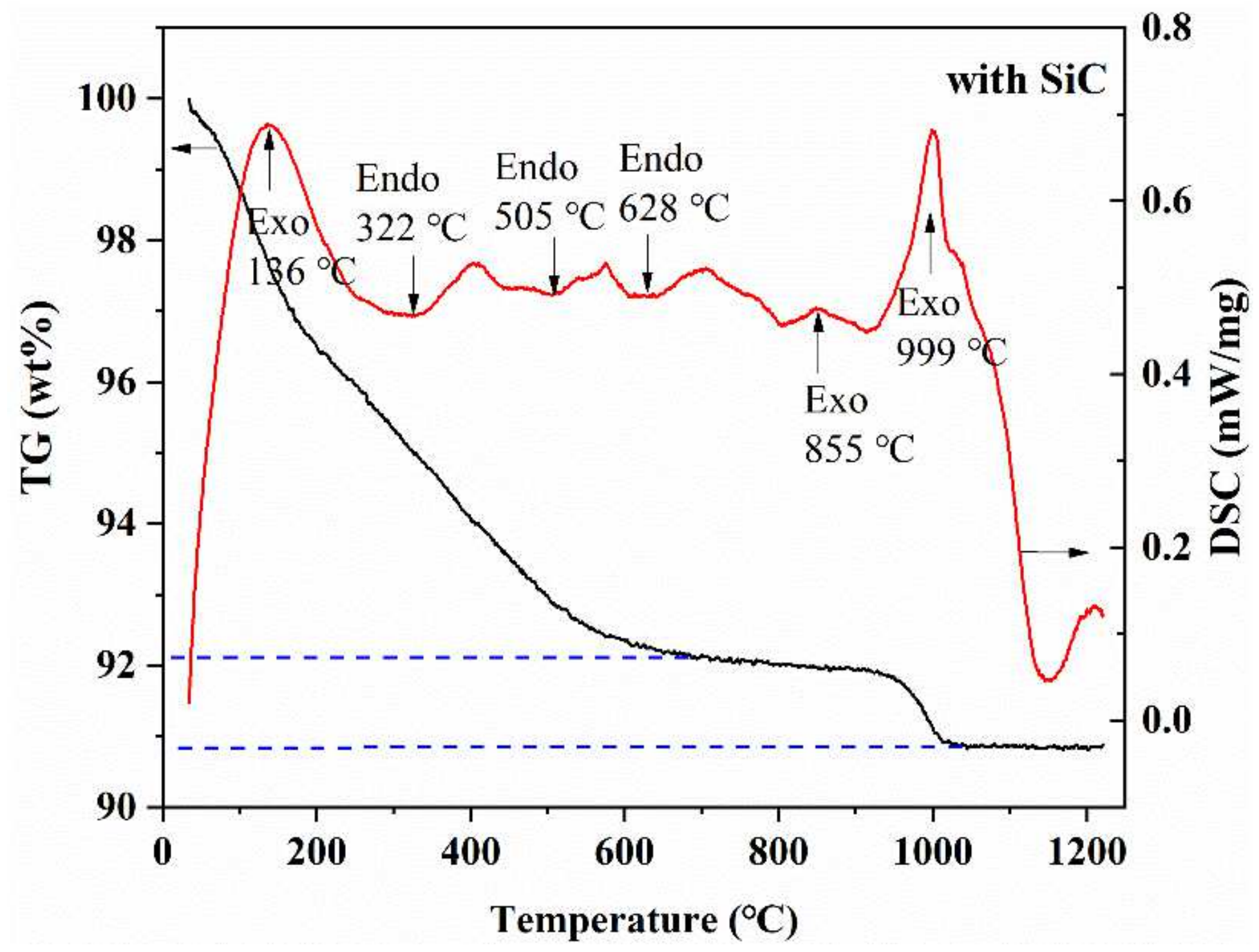

Figure 6

TG/DSC analysis. 